\title{
Profiling Lexical Diversity in College-level Writing
}

\author{
Melanie C. González \\ Salem State University \\ doi: http://dx.doi.org/10.7820/vli.v06.1.González
}

\begin{abstract}
The present paper reports on a study that examined the contribution of lexical frequency to lexical diversity in narrative texts composed by 119 multilingual and monolingual English-speaking students enrolled in first-year college writing courses. The Measure of Textual Lexical Diversity (MTLD) quantified lexical diversity and the BNC-COCA 25 strand in Lextutor's VocabProfile Compleat sorted the words according to frequency band. Overall, results from statistical analyses indicated that sample's lexical diversity was not significantly impacted by the use of high-frequency $(1,000-3,000$ bands) or low-frequency $(9,000+$ bands) terms. Instead, texts showed greater differences in the mid-frequency $(3,000-9,000)$ bands $(p<0.05)$. There were also significant differences between MTLD writers' written productive use of mid-frequency words. Consequently, findings suggest that mid-frequency vocabulary may play a greater role in academic writing quality than the attention it is typically given in the L2 writing classroom.
\end{abstract}

Keywords: second-language writing; second-language vocabulary; lexical diversity; lexical frequency; academic writing.

\section{Introduction}

Over the years, vocabulary-related studies in multilingual (ML) writing scholarship consistently cite the positive influence of lexical diversity on college-level writing quality (Crossley \& McNamara, 2009; Engber, 1995; Friginal, Li, \& Weigle, 2014; Johnson, Acevedo, \& Mercado, 2013). Lexical diversity, which refers to the varied use of unique vocabulary words within a text, manifests itself as "the sophisticated use of vocabulary" and "a variety and range of vocabulary" within holistic rubrics that assess the college writing readiness of ML students (Hawkey \& Barker, 2004). Such criteria point to the need for ML writers to have a large and diverse lexicon from which to purposefully and strategically select words while writing. However, little is known about what vocabulary items actually contribute to the lexical diversity of a text. As a result, writing instructors aiming to help ML writers to improve their students' productive lexicon often must rely on their intuition to determine which words to target for instructional activities. The present study is a first step toward profiling the lexical diversity of college-level writing. 


\section{Literature Review}

\subsection{Lexical Diversity}

In much of the research over the years on the intersection of vocabulary and writing, lexical diversity has emerged as a critical component affecting raters' judgment of academic writing quality. In an early study of first language (L1) writing, Grobe (1981) compared the writing scores of 5th, 8th, and 11th grade students with a variety of syntactic, mechanical, and lexical measures. Results indicated that lexical diversity, or the total number of different words, was the strongest predictor of writing score. Linnarud (1986) found a similar result in a study comparing the compositions of advanced ML and monolingual English-speaking (MES) academic writers. Despite their high level of English proficiency, the ML essays lacked lexical diversity and sophistication. In addition, there was a difference in the frequency of individual words used by the MES and ML learners. The MES writers tended to use more low-frequency adjectives and adverbs, thereby expressing more sophistication and adding diversity to their compositions.

Later studies removed the comparison of MES and ML writer texts and focused on one group or the other to determine aspects of writing quality. For example, Engber (1995) examined the specific relationship between lexical proficiency and reader perception of the overall quality of essays written by ML students and found that error-free lexical diversity had the highest significant correlation to writing score. Using a within-subjects design, Schoonen, van Gelderan, de Glopper, Hulstijn, Simis, Snellings, and Stevenson (2003) compared writing performance and fluency between participants' academic compositions written in their L1 (Dutch) and L2 (English). Their results determined that the writers' L1 compositions demonstrated a higher level of lexical diversity than their L2 essays. Considering the participants were able to achieve higher levels of lexical diversity within their L1 compositions, this result may signal that their smaller L2 lexicons inhibited their ability to vary words within their L2 writing samples.

More recently, in an analysis of a corpus of L1 undergraduate essays, McNamara, Crossley, and McCarthy (2009) found that more proficient writers demonstrated a greater amount of lexical diversity in their essays. The essays earning the highest scores rarely repeated words and contained words that occur less frequently in language. This result suggests that high-proficiency writers have a larger lexicon from which to draw rich, diverse vocabulary items to express ideas. Similarly, Crossley, Salsbury, and McNamara (2012) examined 100 essays by ML writers at three levels of proficiency (low, mid, and high) and found that lexical diversity could rather accurately predict students' English proficiency levels. Finally, Friginal et al. (2014) profiled the qualities of 353 highly rated undergraduate and graduate essays and found that those papers that garnered perfect and near perfect scores correlated to greater lexical diversity.

Thus, empirical research has demonstrated lexical diversity closely relates to writing proficiency. Evaluators are more likely to award points to writers who are able to vary their word choice during the composition process. The studies discussed in this section further indicate that there are clear differences in the lexical diversity profiles of ML and MES compositions. One possible explanation

Vocabulary Learning and Instruction, 6 (1), 61-74. 
for MES writers' ability to vary lexis in text stems from their relatively large vocabulary size as compared to that of ML learners. Therefore, a closer examination of what vocabulary ML writers ought to possess within their lexicons in order to increase lexical diversity is warranted.

\subsection{Lexical Frequency}

When investigating the vocabulary ML writers need for college-level writing tasks, there are generally two approaches researchers and instructors can take (Nation \& Waring, 1997; Nation \& Webb, 2011). The first approach would be to consider how many words exist in the English language. The second could consider how many words their MES peers would likely know. However, the first approach is not a valid measure for vocabulary size because it is extremely unlikely that MES college writers know every word in existence. Therefore, the second approach, to use the words MES writers know and possess within their lexicon is a more feasible measure to use for comparison.

Vocabulary researchers commonly use indices of lexical frequency to operationalize and quantify learners' lexicons for empirical study (Laufer \& Nation, 1995; Nation, 2006). Lexical frequency is a word's particular ranking in terms of how frequently it occurs within corpora of natural language production. The rank is represented in bands of 1,000 words groups and ordered by frequency of use. The first 3,000 words indicate high-frequency words, the next 3,000-9,000 words are considered mid-frequency words, and the remaining words in the 9,000 and above comprise the low-frequency category (Cobb, 2007; Schmitt \& Schmitt, 2014). This classification of words into 1,000 word family bands by their frequency of use operates under the assumptions that (a) high-frequency words are encountered more often in natural language production and therefore are easier to acquire and are highly useful (Meara \& Bell, 2001; Schmitt \& Schmitt, 2014; Stæhr, 2008) and (b) the frequency bands can offer a sampling of the words language users possess within their lexicons and are often used in tests of vocabulary size (Nation, 2006; Nation \& Begler, 2007; Schmitt, Schmitt, \& Clapham, 2001).

Studies of lexical frequency in writing have resulted in a number of useful conclusions for ML writers and their instructors. First, lexical frequency has significant correlations with writing proficiency. ML writers at lower levels of language proficiency tend to use more high-frequency words than writers at higher levels of proficiency or MES students who more often insert words from a wider range of frequency bands into their texts (Crossley \& McNamara, 2009; Johnson et al. 2013; Laufer \& Nation, 1995; Stæhr, 2008). Therefore, studies generally recommend that instructors of ML writers explicitly include vocabulary instruction in the L2 writing classroom in order to stretch ML students' productive lexicons to include words from the lower frequency bands in their writings.

Second, lexical frequency offers a way to evaluate the utility of words based on the percentage of text coverage the various bands achieve. Corpus research has concluded that high-frequency words can cover up to $80-90 \%$ of written English texts, with mid-frequency vocabulary contributing an additional $5-8 \%$ of text coverage, and low-frequency words making up the remaining percentages (Nation, 2006). Such thresholds hold important implications for ML students' abilities to

Vocabulary Learning and Instruction, 6 (1), 61-74. 
comprehend and produce vocabulary within the written domain. Research has shown that 1,000 to 9,000 word family bands are critical to obtaining $98 \%$ text coverage, the minimum figure needed to comprehend academic texts (Laufer \& Ravenhorst-Kalovski, 2010). While a similar threshold is yet to be identified for writing proficiency, it can be inferred that the vocabulary up to the 9,000 level also facilitates academic writing (Stæhr, 2008).

Finally, lexical frequency is also a main indicator of lexical sophistication, a term often utilized in academic writing rubrics such as the TOEFL, IELTS, and English as a second language (ESL) Composition Profile that assess writing proficiency and academic writing readiness. Read (2000) defines lexical sophistication as "the use of technical terms and jargon as well as the kind of uncommon words that allow writers to express their meanings in a precise and sophisticated manner" (p. 200). This definition is based on the operationalization that a sophisticated lexical item is one that does not occur frequently in use. In more pedagogical terms, lexical sophistication is often coded as "big words," "academic words," "technical terms," or "tier 3" words (Beck, McKeown, \& Kucan, 2002; Calderón, 2007; Coxhead, 2000; Schmitt, 2010). These rubrics are based on studies that have found that college-level writing tends to draw more heavily from the mid-and lowfrequency bands than more informal texts (Daller, Van Hout, \& Treffers-Daller, 2003; Hawkey \& Barker, 2004). Studies comparing the lexical frequency profiles between ML and MES college texts have indicated that MES writers produce more lexically sophisticated texts (Crossley \& McNamara, 2009).

\subsection{The Intersection between Lexical Frequency and Lexical Diversity}

In terms of the intersection between lexical frequency and lexical diversity, there is an assumption within the field that a text that produces more low-frequency words would earn a higher score of lexical diversity than a similar text that uses more high-frequency terms (Daller et al., 2003). However, there is scarce, but preliminary, evidence that lexical frequency does not always correlate well with lexical diversity. Laufer (1994) unearthed no significant relationship between learners' increase in the use of lower frequency terms and their lexical diversity scores. Johnson et al.'s (2013) study, however, indicated that the use of lower frequency words, albeit from the 4,000-5,000 frequency bands, did facilitate writing score. In a study of advanced ML and MES college writers, González (2013) found there was only a moderate correlation between lexical frequency and diversity, suggesting that lexically diverse texts do not always require the use of low-frequency, sophisticated words.

These findings suggest that academic writers do not necessarily need to draw from the low-frequency bands in order to achieve the lexical diversity necessary for proficient L2 writing. However, further study of which frequency bands facilitate lexical diversity is needed in order to validate these results.

\section{Research Questions}

Therefore, the examination of college writers' written lexical frequency profiles and how they intersect with lexical diversity has the potential to lend insight 
into possible gaps in their productive vocabulary knowledge. Furthermore, looking at what frequency bands are represented in multilingual (ML) texts as compared to their monolingual English-speaking (MES) peers can help to answer the question on what words to spend instructional time on.

Given the lack of studies profiling lexical diversity in academic compositions, this study took a first step in the hope of filling this gap via the following two research questions:

(1) How do the lexical frequency profiles of advanced multilingual writers' college-level compositions compare to those of their MES peers?

(2) What frequency level(s) is a significant contributor to lexical diversity in college-level compositions?

\section{Methods}

The research goal sought to examine the lexical frequency profile of the lexical diversity present in authentic college-level writing. In order to meet this goal, a corpus of college student-authored texts from four first-year college writing courses was gathered and analyzed using two computerized textual profilers. Regression and difference in mean statistical analyses targeted the answers to the two research questions. The following sections provide further detail on the methods employed.

\subsection{Corpus Collection}

In order to ensure that the corpus included texts from both multilingual (ML) and MES writers, first-year writing classes that contained both populations of writers at four universities where the researcher had professional contacts were targeted. Student writers were given a demographic survey in order to identify them as a ML or MES writer. The resulting corpus contained 377 texts.

Given that the vocabulary of a text is highly dependent on the genre, prompt, and length of a text, the corpus was culled according to these criteria in order to control for students' word choice and subsequently the lexical frequency and diversity profiles. First, the corpus was restricted to the final drafts of narrative essays with the topic of "Myself as a Writer," which was the first writing assignment required in the targeted writing courses to provide insights about the students' abilities as a writer to the instructor. From this narrowed corpus, texts that were a minimum of 500 words in length were selected. This process yielded 119 texts (from the original 377) for analysis that controlled for the genre, prompt, and text length. Of these 119 texts, 65 were written by MES students and 54 were written by ML students. Overall, 17 first languages were represented within the corpus (see Table 1).

\subsection{Textual Profiling}

In order for the two computerized textual profilers to recognize and tag the words accurately, minor mechanical errors (such as spelling, extra spaces, and consecutive 
Table 1. First Languages Represented in the Corpus

\begin{tabular}{lc}
\hline First language & $n$ \\
\hline Arabic & 1 \\
Amharic & 1 \\
Chinese & 21 \\
English & 64 \\
French & 1 \\
Hindi & 2 \\
Hmong & 4 \\
Indonesian & 1 \\
Japanese & 2 \\
Kannada & 1 \\
Korean & 2 \\
Portuguese & 1 \\
Russian & 1 \\
Spanish & 10 \\
Tagalog & 1 \\
Vietnamese & 6 \\
\hline
\end{tabular}

repeated words) within each text in the corpus were corrected. These fixes were necessary in order to ensure that mechanical errors would not be mistaken as off-list words and consequently skew the profiles of lexical frequency and lexical diversity. Since the texts were final drafts (and thus inferred to have undergone some proofreading on the part of the authors), the number of mechanical errors needing correction were minimal.

The texts were then entered into the BNC-COCA 25 profiler within the VocabProfile Compleat tool available in Lextutor (Cobb, n.d.), which counted the number of words into 1,000 word family bands up to the 25,000 word family and off-list bands. The resulting figures were further classified as high-, mid-, or lowfrequency vocabulary using Schmitt and Schmitt's (2014) broad band categorizations with high-frequency terms falling within the first 1,000 to 3,000 word family bands, mid-frequency terms in the 3,000 to 9,000 word family bands, and lowfrequency terms lying in the 9,000 word family band and above range and off-list word families. These totals created the lexical frequency variable.

The Measure of Textual Lexical Diversity (MTLD) quantified the lexical diversity of the texts (McCarthy \& Jarvis, 2010, available in the Coh-Metrix, Graesser, McNamara, Louwerse, \& Cai, 2004). A critical limitation of indices measuring lexical diversity is that scores are greatly impacted by text length. In other words, as the total number of words in a text rises, so does the likelihood of word repetition, thereby reducing lexical diversity. In validation studies, the MTLD has shown to account for this fatal flaw by sampling strings of texts forward and backward multiple times in order to provide a more accurate measure of lexical diversity (McCarthy \& Jarvis, 2010). MTLD scores typically range between 70 and 120, where the higher scores equal greater lexical diversity. Although the present study's corpus was restricted to texts with similar word counts, there is nonetheless some variation in text length and as such, the MTLD was chosen to measure the lexical diversity. 
The specific quantitative analyses run on the two variables and are discussed in conjunction with the results of these analyses in the subsequent section.

\section{Results}

Descriptive results of the corpus $(n=119)$ revealed that, on average, text length ranged between 500 and 600 tokens in length with a mean token count of 557. ML writers' $(n=54)$ texts averaged 556 tokens in length while MES writers' $(n=65)$ texts had a mean token count of 559. In terms of lexical frequency, ML writers averaged a total of 546 high-frequency words, 7 mid-frequency words, and 2 words from the low-frequency bands. The MES writers' texts utilized an average of 541 highfrequency words, 14 mid-frequency words, and 3 low-frequency words (see Table 2).

\subsection{Research Question 1}

The first research question targeted the mean differences between ML and MES writers' profiles of lexical frequency and lexical diversity. A one-way analysis of variance (ANOVA) revealed that ML writers significantly used more highfrequency words than their MES peers $\left(\mathrm{F}_{2,117}=54.13, p<0.00, \eta^{2}=0.57\right)$. In contrast, MES writers used significantly more mid-frequency words within their texts than ML writers $\left(\mathrm{F}_{2,117}=15.12, p<0.00 \eta^{2}=0.27\right)$. There was no significant difference between ML and MES texts' use of low-frequency words in their compositions. For lexical diversity, MES writers' texts exhibited significantly greater lexical diversity than the texts composed by ML writers $\left(\mathrm{F}_{2,117}=5.06, p<0.05, \eta^{2}=0.11\right.$; see Table 3$)$.

\subsection{Research Question 2}

The second research question sought to determine which broad lexical frequency bands contributed to lexical diversity. Multiple regression analysis revealed that lexical frequency explained about $27 \%$ of the variation in lexical

Table 2. Descriptive Data by Language Designation

\begin{tabular}{lcrc}
\hline & Designation & $\mathrm{M}$ & $\mathrm{SD}$ \\
\hline High frequency & $\mathrm{ML}$ & 546.43 & 8.26 \\
(K1-K2) & MES & 541.20 & 8.29 \\
& Total & 544.06 & 12.46 \\
Mid-frequency & ML & 7.09 & 6.34 \\
(K3-K8) & MES & 14.45 & 6.01 \\
& Total & 10.51 & 6.81 \\
Low frequency & ML & 2.39 & 2.1423 \\
(K9+) & MES & 3.20 & 3.6648 \\
& Total & 2.77 & 3.0460 \\
MTLD & ML & 69.54 & 17.35 \\
& MES & 79.95 & 12.90 \\
& Total & 74.38 & 15.84 \\
\hline
\end{tabular}

MES, monolingual English-speaking; ML, multilingual. 
diversity score $\left(\mathrm{F}_{2,117}=4.75, p<0.05\right)$. The regression model correctly classified 105 of the 119 essays' lexical diversity based on lexical frequency. The regression analysis also revealed that mid-frequency vocabulary was the only significant predictor of lexical diversity (beta $=0.42, p<0.05$; see Table 4). In other words, as lexical diversity score increased, there was an uptick in likelihood of a mid-frequency word being deployed within the composition.

\section{Discussion}

The findings that ML college writers' texts (when composing in the same genre and on the same topic) employed more high-frequency words, fewer midfrequency words, and exhibited less lexical diversity than texts composed by their MES peers are in line with previous studies with similar conclusions (see Crossley \& McNamara, 2009, 2012). However, the result that there was no difference between both groups' use of low-frequency words is noteworthy. It suggests that there may be a gap in ML writers' productive knowledge of mid-frequency terms that in turn affects the lexical diversity of their texts, which, as results indicate, is greater when mid-frequency words are present. The result that MES writers used, on average, twice the number of mid-frequency terms in their texts provides some evidence to support the unique contribution of these words to the lexical diversity of a text.

Table 3. One-Way Analysis of Variance of Lexical Frequency Levels and Diversity by Language Designation

\begin{tabular}{|c|c|c|c|c|c|c|c|}
\hline & Source & SS & df & MS & $\mathrm{F}$ & Sig. & $\eta^{2}$ \\
\hline \multirow[t]{3}{*}{ High frequency } & Between groups & 3710.49 & 2 & 3710.49 & 54.13 & 0.00 & 0.57 \\
\hline & Within groups & 2810.25 & 117 & 68.54 & & & \\
\hline & Total & 6520.74 & 119 & & & & \\
\hline \multirow[t]{3}{*}{ Mid-frequency } & Between groups & 579.97 & 2 & 579.97 & 15.12 & 0.00 & 0.27 \\
\hline & Within groups & 1572.78 & 117 & 38.36 & & & \\
\hline & Total & 2152.74 & 119 & & & & \\
\hline \multirow[t]{3}{*}{ Low frequency } & Between groups & 7.00 & 2 & 7.00 & 0.75 & 0.39 & 0.02 \\
\hline & Within groups & 382.68 & 117 & 9.33 & & & \\
\hline & Total & 389.67 & 119 & & & & \\
\hline \multirow[t]{3}{*}{ MTLD } & Between groups & 1158.43 & 2 & 1158.43 & 5.06 & 0.03 & 0.11 \\
\hline & Within groups & 9382.19 & 117 & 228.83 & & & \\
\hline & Total & 10540.62 & 119 & & & & \\
\hline
\end{tabular}

MTLD, Measure of Textual Lexical Diversity.

Table 4. Multiple Regression Predicting Lexical Diversity

\begin{tabular}{|c|c|c|c|c|c|c|c|c|}
\hline \multirow{2}{*}{\multicolumn{2}{|c|}{ Model }} & \multirow[t]{2}{*}{$B$} & \multirow[t]{2}{*}{ SE } & \multirow[t]{2}{*}{ Beta } & \multirow[t]{2}{*}{$\mathrm{t}$} & \multirow[t]{2}{*}{ Sig. } & \multicolumn{2}{|c|}{$95 \% \mathrm{Cl}$} \\
\hline & & & & & & & LB & UB \\
\hline \multirow[t]{4}{*}{1} & (Constant) & 65.7 & 122.00 & & 0.54 & 0.60 & -181.07 & 312.48 \\
\hline & High frequency & -0.01 & 0.25 & -0.01 & -0.038 & 0.97 & -0.51 & 0.49 \\
\hline & Mid-frequency & 0.93 & 0.415 & 0.42 & 2.24 & 0.03 & 0.09 & 1.77 \\
\hline & Low frequency & 1.24 & 0.75 & 0.24 & 1.65 & 0.11 & -0.28 & 2.75 \\
\hline
\end{tabular}


There are a few potential explanations as to why mid-frequency vocabulary facilitates lexical diversity. First and foremost, mid-frequency words that lie between the 3,000 and 9,000 word family bands contribute $5-8 \%$ to the $95-98 \%$ written textual coverage, a key threshold in the ability to comprehend academic texts (Laufer \& Ravenhorst-Kalovski, 2010; Nation, 2006). In addition, word lists of academic vocabulary such as Coxhead's (2000) Academic Word List and Gardner and Davies' (2014) Academic Vocabulary List contain a good deal of words that lie within the mid-frequency vocabulary range and are utilized across academic subject areas. Moreover, many mid-frequency terms (e.g., endow, bestow) are synonyms, hypernyms, and hyponyms for high-frequency (e.g., give) and lowfrequency words (e.g., bequeath) that can add sophistication, specificity, and diversity to a text (Ferris, 1994). Consider the following two paragraphs extracted from this study's corpus in which the mid-frequency vocabulary has been bolded and low-frequency words italicized for emphasis:

\section{Excerpt 1}

Writing is an important tool to have in life and can be applicable to various occupations. Writing is a way of formulating your thoughts and observations on paper with no requirement on the subject matter. In the past I have been exposed to multiple writing experiences that required that I be clear and concise in my diction. I have had some encouraging and frustrating experiences, but overall I am determined to master the art of composition.

Excerpt 1 is composed by a MES writer and had an overall lexical diversity score of 95.46. In this 71-token snippet, the writer used 42 high-frequency words, two mid-frequency words, and one low-frequency word.

\section{Excerpt 2}

I believe I have the potential of being a good writer. I could not speak or understand English when I entered school in the US, but I was determined to become fluent in this new language. I was previously nervous about writing, but as I had many writing opportunities, I continued to improve each time. Who I am as a person describes who I am as a writer. I have always been a determined type and that can show in my writing.

Excerpt 2, composed by a ML writer, has an overall lexical diversity index of 87.85 . Of the 67 tokens present, 45 are high-frequency words, one is a mid-frequency word, and one is a low-frequency word (the proper noun of English). These two excerpts from the study's corpus exemplify where using a mid-frequency word in comparable sentences can potentially add diversity and sophistication to a text: the MES writer states, "I have been exposed to multiple writing experiences that required that I be clear and concise"; whereas their ML peer writes: "but as I had many writing opportunities, I continued to improve each time." It can be argued that the term concise more specifically refers to a positive quality of writing, a term that is more specific than the general but positive verb improve that the ML writer employs. 
It should also be noted that although the number of low-frequency terms present in the two excerpts are the same (diction in Excerpt 1 and English in Excerpt 2), more qualitative judgments might perceive the use of diction over English as a more sophisticated term despite both being categorized as low-frequency. This example points to the need for further qualitative analysis to be included in future studies.

\section{Applications to Pedagogy}

In terms of pedagogy, the general recommendation has been for ESL instructors to explicitly teach the high-frequency vocabulary (the first 2,000-3,000 word families) and to use more implicit methods such as exposure through extensive input to provide ML students with the mid- and low-frequency terms needed to expand their lexicon. However, as Schmitt (2010) states, "it is clearly not realistic for learners to acquire the lexis beyond the 2,000 level without a great deal of help" (p. 70). Yet, when instructors are asked to identify words outside of high-frequency terms, it is often the low-frequency items that make into lesson plans, which often relates more to students' comprehension of the topic at hand. Such approaches ignore the wide range of mid-frequency vocabulary that comprises a good deal of the academic language research has shown is necessary for college-level literacy events and practices. Furthermore, research has shown that in order for vocabulary to not be a problem for ML students, the mastery of many knowledge aspects of the words within the frequency bands up to the 9,000 word family level is critical for productive use (Schmitt \& Schmitt, 2014). In other words, students with only receptive or partial knowledge of mid-frequency words are unlikely to deploy them in their compositions.

Consequently, more research has been advocating for the explicit instruction and reinforcement of all types of vocabulary, including mid-frequency terms, in order to equip ML students with the lexical tools they need for English-medium college coursework (see Folse, 2004, 2008; Schmitt, 2010; Schmitt \& Schmitt, 2014). This trend is particularly evident in the "tiering" approach to vocabulary instruction gaining popularity in the U.S. primary and secondary education research base that recommends targeting "tier 2" word for instruction (see Beck et al., 2002 and Calderón, 2007). The conclusions of this study validate a similar, but more frequency-based approach to vocabulary instruction within the L2 writing classroom and advocate for explicit attention to and fortification of midfrequency vocabulary in order to begin filling in the gaps within ML writers' productive lexicons.

In addition to targeting mid-frequency vocabulary for instruction, the skills involved in diversifying lexis during the composition process also deserve explicit focus in the L2 writing classroom. Learners can be made aware of the role lexical diversity plays in their writing quality through the analysis of model texts as well as instructor think-alouds or talk-alouds demonstrating and modeling the decision-making involved when choosing words. Furthermore, instructors can design exercises and activities that practice rephrasing and identifying synonyms, hypernyms, and hyponyms that add diversity and sophistication to the text. ML students can also utilize various online lexical profilers (such as Lextutor) to obtain 
a visual of the spread of their vocabulary during the proofreading, editing, and revision process to target overly repeated words that could be replaced. Finally, it cannot be assumed that students know how to make use of a thesaurus or the synonyms feature in word processing software that could provide assistance in identifying appropriate synonyms. Instructors ought to model, demonstrate, and engage in practice with these tools.

\section{Limitations and Future Research}

There are some cautions that apply to the present findings. The corpus was relatively small $(n=119)$ and limited to the narrative genre and the topic of "Myself as a Writer." Had the study included a larger and wider range of different genres and topics, findings may shift as vocabulary is highly dependent on these two variables. In addition, the corpus was compiled from first-year writing courses at U.S. universities. As such, conclusions may not be as applicable to writings produced in other contexts, such as in elementary, secondary, or other L2 classrooms that target lower proficiency levels, as these contexts may contain different expectations for vocabulary in writing. Finally, any study using corpus tools for analysis is beholden to the corpus it utilized. The lexical frequency variable was based on British National Corpus and Corpus of Contemporary American English, which includes a wide range of informal and formal topics as well as utilizes the word family as the unit of counting. If frequency analysis had used a different corpus or the lemma as a counting unit, the lexical frequency profiles might shift.

In order to address these limitations as well as continue to tease out the contribution of lexical diversity to writing quality, there are a few avenues for further study. First, the conclusions from the present study could be strengthened through qualitative analyses such as inviting writing instructors to rate the lexical quality of a corpus and interviewing them regarding what aspects impact their ratings, and listing which words they feel contribute most to the lexical quality of a text. Further quantitative analyses are also warranted. For example, including independent measures of the general receptive and productive vocabulary sizes of student writers could isolate the impact of mid-frequency vocabulary on lexical diversity as well as illuminate if in fact ML writers do possess gaps in this range of their lexicons. Finally, experimental methods such as manipulating the lexical frequency and/or diversity in texts and asking writing instructors to judge and rate the resulting quality may provide further insight into the vocabulary needed to perform college-level writing.

\section{Conclusion}

The present study investigated the influence lexical frequency imparts to lexical diversity in multilingual (ML) and MES first-year college student writing. Quantitative analyses indicate that mid-frequency vocabulary has a greater impact on the lexical diversity of a text and that there are significant differences between ML and MES writers' use of these words. These conclusions support the explicit teaching of mid-frequency vocabulary words and lexical diversity skills in the L2 writing classroom. 


\section{References}

Beck, I., McKeown, M.G., \& Kucan, L. (2002). Bringing words to life: Robust vocabulary development. New York, NY: Guilford.

Calderón, M. (2007). Teaching reading to English language learners: Grades 6-12. Thousand Oaks, CA: Corwin Press.

Cobb, T. (n.d.). Compleat Lexical Tutor [Online Software]. Available from http:// www.lextutor.cal

Cobb, T. (2007). Computing the vocabulary demands of L2 reading. Language Learning \& Technology, 11(3), 38-63. Retrieved from http://1lt.msu.edu/ voll1num $3 /$ cobb/

Coxhead, A. (2000). A new academic word list. TESOL Quarterly, 34(2), 213-238. doi: $10.2307 / 3587951$

Crossley, S. \& McNamara, D.S. (2012). Predicting second language writing proficiency: The roles of cohesion and linguistic sophistication. Journal of Research in Reading, 35(2), 1-21. doi: 10.1111/j.1467-9817.2010.01449.x

Crossley, S.A., \& McNamara, D.S. (2009). Computational assessment of lexical differences in L1 and L2 writing. Journal of Second Language Writing, 18(2), 119-135. doi:10.1016/j.jslw.2009.02.002

Crossley, S.A., Salsbury, T., \& McNamara, D.S. (2012). Predicting the proficiency level of language learners using lexical indices. Language Testing, 29(2), 243-263. doi: 10.1177/0265532211419331

Daller, H., Van Hout, R., \& Treffers-Daller, J. (2003). Lexical richness in the spontaneous speech of bilinguals. Applied Linguistics, 24(2), 197-222. doi:10.1093/applin/24.2.197

Engber, C. (1995). The relationship of lexical proficiency to the quality of ESL compositions. Journal of Second Language Writing, 4(2), 139-155. Retrieved from https://www.journals.elsevier.com/journal-of-second-language-writing/

Ferris, D. (1994). Lexical and syntactic features of ESL writing by students at different levels of L2 proficiency. TESOL Quarterly, 28(2), 414-420. doi: $10.2307 / 3587446$

Folse, K. (2004). Vocabulary myths. Ann Arbor, MI: University of Michigan Press.

Folse, K. (2008). Myth 1: Teaching vocabulary is not the writing teacher's job. In J. Reid (Ed.), Writing myths: Applying second language research to classroom teaching (pp.1-17). Ann Arbor, MI: University of Michigan Press.

Friginal, E., Li, M., \& Weigle, S.C. (2014). Revisiting multiple profiles of learner compositions: A comparison of highly rated NS and NNS essays. Journal of Second Language Writing, 23(1), 1-16. doi:10.1016/j.jslw.2003.09.001

Gardner, D., \& Davies, M. (2014). A new academic vocabulary list. Applied Linguistics, 35(3), 305-327. doi:10.1093/applin/amt015

González, M.C. (2013). The intricate relationship between measures of vocabulary size and lexical diversity as evidenced in non-native and native speaker

Vocabulary Learning and Instruction, 6 (1), 61-74. 
academic compositions (Doctoral dissertation). Retrieved from http://stars. library.ucf.edu/etd/2633. (CFE0004852)

Graesser, A.C., McNamara, D.S., Louwerse, M.M., \& Cai, Z. (2004). Coh-Metrix: Analysis of text on cohesion and language. Behavioral Research Methods, Instruments, and Computers, 36, 193-202. Retrieved from http://129.219.222.66/ Publish/pdf/McNamara_Graesser_Coh-Metrix.pdf

Grobe, C. (1981). Syntactic maturity, mechanics, and vocabulary as predictors of quality ratings. Research in the Teaching of English, 15(1), 75-85. Retrieved from https://eric.ed.gov/?id=EJ242214

Hawkey, R., \& Barker, F. (2004). Developing a common scale for the assessment of writing. Assessing Writing, 9(2), 122-159. doi:10.1016/j.asw.2004.06.001

Johnson, M., Acevedo, A., \& Mercado, L. (2013). What vocabulary should we teach?: Lexical frequency profiles and lexical diversity in second language writing. Writing \& Pedagogy, 5(1), 82-103. doi: 10.1558/wap.v4i5.1

Laufer, B. (1994). The lexical profile of second language writing: Does it change over time? RELC Journal, 25(2), 21-33. Retrieved from http://journals. sagepub.com/doi/pdf/10.1177/003368829402500202

Laufer, B., \& Nation, I.S.P. (1995). Vocabulary size and use: Lexical richness in L2 written production. Applied Linguistics, 16(3), 307-322.

Laufer, B., \& Ravenhorst-Kalovski, G. (2010). Lexical threshold revisited: Lexical text coverage, learners' vocabulary size and reading comprehension. Reading in a Foreign Language, 22(1), 15-30. Retrieved from http://files.eric. ed.gov/fulltext/EJ887873.pdf

Linnarud, M. (1986). Lexis in composition: A performance analysis of Swedish learners' written English. Malmö, Sweden: Liber Förlag Malmö.

Meara, P. \& Bell, H. (2001). P_Lex: A simple and effective way of describing the lexical characteristics of short L2 texts. Prospect, 16(3), 5-19. Retrieved from http://www.lognostics.co.uk/vlibrary/meara\&bell2001.pdf

McNamara, D.S., Crossley, S.A., \& McCarthy, P.M. (2009). Linguistic features of writing quality. Written Communication, 27(1), 57-86. doi:10.1177/0741088309351547

McCarthy, P.M., \& Jarvis, S. (2010). MTLD, voc-D, and HD-D: A validation study of sophisticated approaches to lexical diversity assessment. Behavior Research Methods, 42, 381-392. doi:10.3758/BRM.42.2.381

Nation, I.S.P. (2006). How large a vocabulary is needed for reading and listening? Canadian Modern Language Review, 63(1), 59-82. Retrieved from http:// www.victoria.ac.nz/lals/about/staff/publications/paul-nation/2006-Howlarge-a-vocab.pdf

Nation, I.S.P., \& Beglar, D. (2007). A vocabulary size test. The Language Teacher, 31(7), 9-13. Retrieved from http://www.victoria.ac.nz/lals/about/staff/ publications/paul-nation/2007-Beglar-TLT.pdf

Nation, I.S.P., \& Waring, R. (1997). Vocabulary size, text coverage, and word lists. In N. Schimitt \& M. McCarthy (Eds.), Vocabulary: Description, acquisition 
and pedagogy (pp. 6-19). Cambridge: Cambridge University Press. Retrieved from http://www.lextutor.ca/research/nation_waring_97.html

Nation, I.S.P., \& Webb, S. (2011). Researching and analyzing vocabulary. Boston, MA: Heinle-Cengage.

Read, J. (2000). Assessing vocabulary. Cambridge: Cambridge University Press. Retrieved from http://www.cup.es/servlet/file/store6/item2466355/version1/ item_9780521627412_frontmatter.pdf

Schmitt, N. (2010). Researching vocabulary: A vocabulary research manual. New York, NY: Palgrave MacMillan.

Schmitt, N., \& Schmitt, D. (2014). A reassessment of frequency and vocabulary size in L2 vocabulary teaching. Language Teaching, 47(4), 484-503. doi:10.1017/S0261444812000018

Schmitt, N., Schmitt, D., \& Clapham, C. (2001). Developing and exploring the behaviour of two new versions of the Vocabulary Levels Test. Language Testing, 18(1), 55-88. doi:10.1177/026553220101800103

Schoonen, R., van Gelderen, A., de Glopper, K., Hulstijn, J., Simis, A., Snellings, P., \& Stevenson, M. (2003). First language and second language writing: The role of linguistic knowledge, speed of processing, and metacognitive knowledge. Language Learning, 53(1), 165-202. doi:10.1177/13670069030070010201

Stæhr, L.S. (2008). Vocabulary size and the skills of listening, reading and writing. Language Learning Journal, 36(2), 139-152. doi: 10.1080/09571730802389975 